\title{
E-Learning for empowering the rural people in Bangladesh
}

\author{
Opportunities and challenges
}

\author{
Mannan Mridha, Gunnar Nihlen, Björn-Erik \\ Erlandsson, \\ The Royal Institute of Technology, KTH, \\ Stockholm, Sweden \\ Amirul Alam Khan \\ Board of Intermediate and Secondary Education, Jessore, \\ Bangladesh \\ Mohammad Saiful Islam \\ BSM Medical University, Dhaka, Bangladesh
}

\author{
Nazneen Sultana \\ Grameen Communications, Dhaka, Bangladesh, \\ Sultan Reza \\ Grameen Phone, \\ Dhaka, Bangladesh \\ M.B. Srinivas \\ Birla Institute of Technology, \\ Hyderabad, India
}

Abstract - Inadequate educational resources, insufficient and unqualified teachers and health care providers, and lack of community involvement, are some of the causes that contribute to the poor state of education and health in rural Bangladesh. This is although, it is well known that, access to quality education and scientific knowledge is essential for creating economic growth and sustainable human development, including poverty alleviation and improvement of human health. In all countries and in the developing countries in particular, there is a need to employ Information and Communication Technology, ICT to gain global access to learning. ICT can address issues of educational equity, social exclusion and can deliver a more effective and accessible educational opportunities. It can also reduce cost of reaching and educating many rural students who are deprived of creative education due to lack of qualified teaching force. In Bangladesh, the education curriculum has been modernized to meet an international standard. For various reasons, qualified teachers are not keen to move to rural areas. The same is true in areas of health sectors where qualified medical doctors are not willing to move to rural areas. Therefore, we find enormous potentials for contribution of e-Learning and eHealth in empowering the rural educators as well as health care providers. A pilot project to test the potentials of eLearning is implemented at a village Nohata in Magura district in Bangladesh (www.nuhat.org). Started in 2006, it has been using ICT tools to communicate, learn, and access international quality educational content. International quality teachers have been conducting teaching using videoconference system. Various relevant e-Learning aids have been developed to meet the local needs and conditions, you tube programmes covering different topics are carefully selected to meet the appropriate requirement of different target groups. The links are downloaded so that the students, the teachers, health workers, patients can follow the links off line, as many times as they want and discuss among themselves. The ICT tools are also being used to improve access to health care; enhance the quality of service delivery; improve the effectiveness of public health and primary care interventions; improve the shortage of health professionals through collaboration and training. ICT tools are offering solutions for emergency medical assistance, long-distance consultation, supervision quality assurance, and education and training for healthcare professionals and providers. The main challenges are to empower the rural people through creating locally relevant content for improving proficiency in English language, Mathematics, Science and Health care application and services considering the sociocultural factors, to achieve health, education and economic development. Through careful selection and creation of relevant e-Learning materials, we intend to develop the rural community using the potential of rural people and adopting participatory approaches for building knowledge, skills and capacity.

\section{Keywords-}

e-learning in developing countries, rural empowerment, relevant content, e-health, rural health quality improvement

\section{INTRODUCTION}

The population in Bangladesh is predominantly rural, with almost 80 percent living in rural areas, has limited access to education, health care, clean drinking water and proper hygiene. As a result of health problems or natural disasters, they are at risk of sliding deeper into poverty. Women and girls are among the poorest of the rural poor. They suffer from discrimination, have few earning opportunities, and their nutritional intake is often inadequate. The country's geographical and demographic characteristics are among the main causes of rural poverty in Bangladesh. Although, it is clear that healthy and educated citizen is better suited for increased productivity as part of the workforce, most rural schools lack qualified teachers and rural health care facilities 
lack well trained health care providers. There is a serious shortage of teachers to teach English language and science to reach the objectives as describe in the national curriculum. Education qualities differ across societies, and requires the combined efforts of government, the private sector, the public themselves to ensure both the accessibility and affordability of international quality education services [1,2]. Inadequate resources hurt the quantity and quality of teachers in schools, where the teacher to student ratio above 1:60 [1]. More than half of schools have inadequate infrastructure, and lack modern learning materials. Although, recently the national text books have been modernized and are given to all students free of charge, most of the existing teachers are not well trained to teach the content and many do not even understand the material they teach. Chronic recruitment of unqualified teachers, primarily due to cronyism, forms a major impediment to school-level efforts to improve quality in education [1]. Existing teachers training has not adequately increased teachers' capabilities [2]. Additionally, many head teachers in Bangladesh schools do not assume their leadership roles, due to insufficient resources, training and time. For various reasons, rural school students have more than 5 times lesser chances of going into higher education than the urban ones. The unequal distribution of wealth, health care services and educational opportunities have meant that the rural people can hardly benefit from the economic progress though, in the largely agricultural based economy, they are the true engines $[2,3]$.

Rapid development of technologies and computers have changed methods of education and training globally. The use of ICT tools is one of major trends in the field of human resource development. E-Learning is defined as the acquisition and use of knowledge, distributed and facilitated primarily by electronic means [4]. E-learning technologies are used to improve learner's skills and knowledge from many at any time and as many times as required. Learners can complete training when it is least disruptive to their schedule.

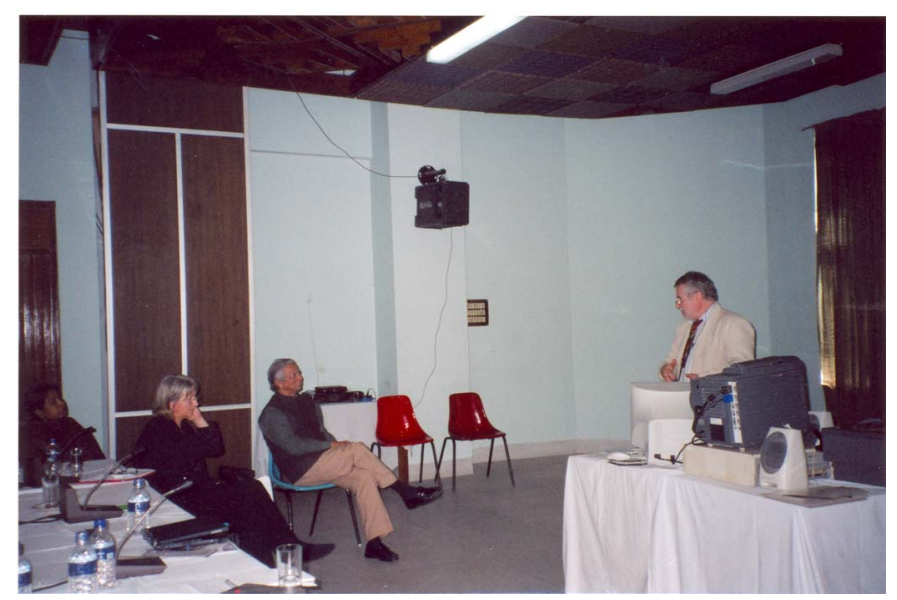

Picture 1: Together with Dr. Person from KTH, Sweden and Dr. Mohammad Yunus from Grameen Bangladesh, in 2004, we started our journey to employ ICT tools for rural development.
The methods can increase learner's interest; Deliver contents clearly and Feedback students easily. Due to these advantages, the popularity of e-Learning has dramatically increased over the past few years. The increased investment in e-Learning has led us to be concerned with the performance and efficiency in terms of Cost efficiency, Learner satisfaction and Learning resources [4]. Education in Bangladesh have been textbook based due to lack of experimental, and technological resources, therefore, the teachers lack confidence to manage technology. They are largely unwilling to change the traditional learning atmosphere to welcome e-Learning. Poor level of competency in the English language among students and teachers is another factor that contributes to the unreceptive attitude. More than 60 percentages of the university teacher and students are not familiar with e-learning [5]. An international, multidisciplinary team of experts from Sweden, India and Bangladesh have been collaborating to apply ICT tools for rural development.

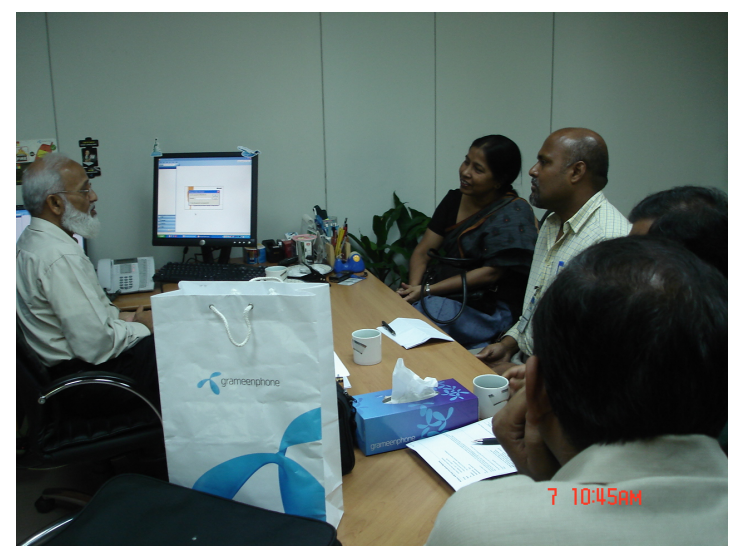

Picture 2: Dr. Mridha from KTH, Sweden, together with Mrs. Nazneen Sultana from Grameen Communications, Eng.

Yahya from Grameen Phone, Dr. Islam from BSM Medical University, and Dr. Srinivas from BITS, Hyderabad, India collaborated to set up the first ICT center for rural development at Nohata, Magura in Bangladesh.

\section{PURPOSE OF THE WORK}

The partners implemented the rural ICT Centre to:

a) Learn from the rural schools and health care providers about the real challenges, priorities and needs and assess the needs in relation to the local conditions, to determine the type of e-Learning and e-Health activities required.

b) Find the level of local capacity available to use the technology effectively, motivate the beneficiaries, end users and local communities to be involved in the development of the ICT solutions to improve education and health care.

c) Create appropriate education and health awareness content and methods to address the urgent issues, considering social and economic contexts, and local conditions.

d) Evaluate the efficiency and sustainability of the system, communication platform and the content and analyse its cost and benefits relative to other alternatives in a way that 
improves the quality of interaction and dialogue among the various stakeholders.

\section{METHOD}

In selecting technology and methods, we addressed some important issues such as, need for collaboration between international partners and experts from different disciplines, end-user acceptance, maintenance of communication infrastructure, adjusting the software and hardware solutions to the local needs and conditions, leveraging easy to use and flexible applications based on real end-user needs, communication costs and service fees for financial sustainability of ICT applications in low resource settings. We carefully considered some important lessons learned from our earlier work, such as to: keep the technology simple and relevant; make it manageable by the local team; involve users by demonstrating benefit; strengthen capacity to use, work and develop effective ICTs; introduce greater monitoring and evaluation. Another important element of the work has been to continue to research and share learning about what works, and what fails, in order to ensuring that all people who make use of the e-Learning system -teachers, students, patients and citizens benefit. To create a well-designed, learner-centered, interactive, affordable, efficient, flexible, meaningful and facilitated e-Learning environment we organize regular meetings and seminars with international collaboration between the Royal institute of Technology in Sweden, Grameen Communications and Grameen Phone and BSMU University in Bangladesh and Birla Institute of Technology, Hyderabad, India.

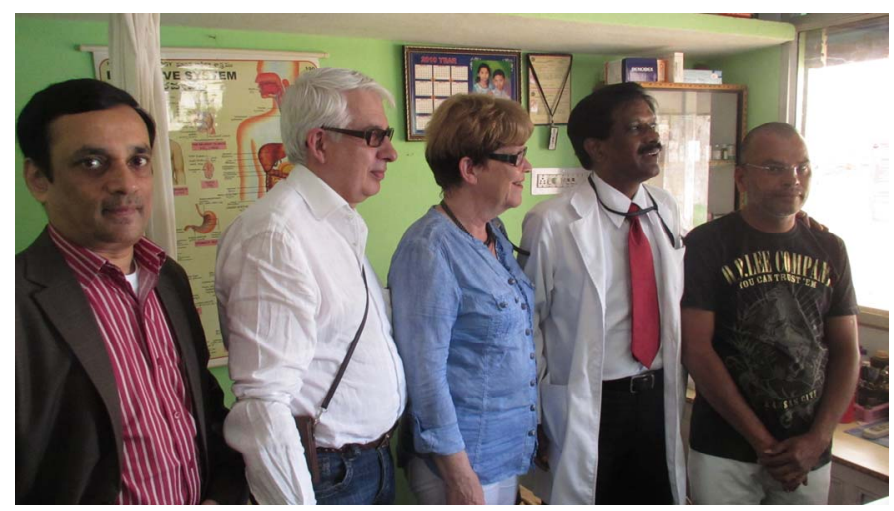

Picture 3: International and multidisciplinary collaboration is essential for successful implementation of ICT tools for rural empowerment.

Multidisciplinary team of experts do the Planning, Selection, Creation, Evaluation and Dissemination work (PSCED) of relevant content to provide e-Health and eLeaning services for rural empowerment. The rural ICT centre is managed by 3 teams, i) for managing ICT infrastructure and training, ii) managing e-Health services, including diagnosis and treatment advice, awareness creation and point of care delivery where health workers visit the patients and connect them with medical experts and iii) e-Learning managers, who download, store and archive contents, organize and monitor the learning sessions, group discussions, personal reflections and evaluations. Figure 1 below shows the organization structure.

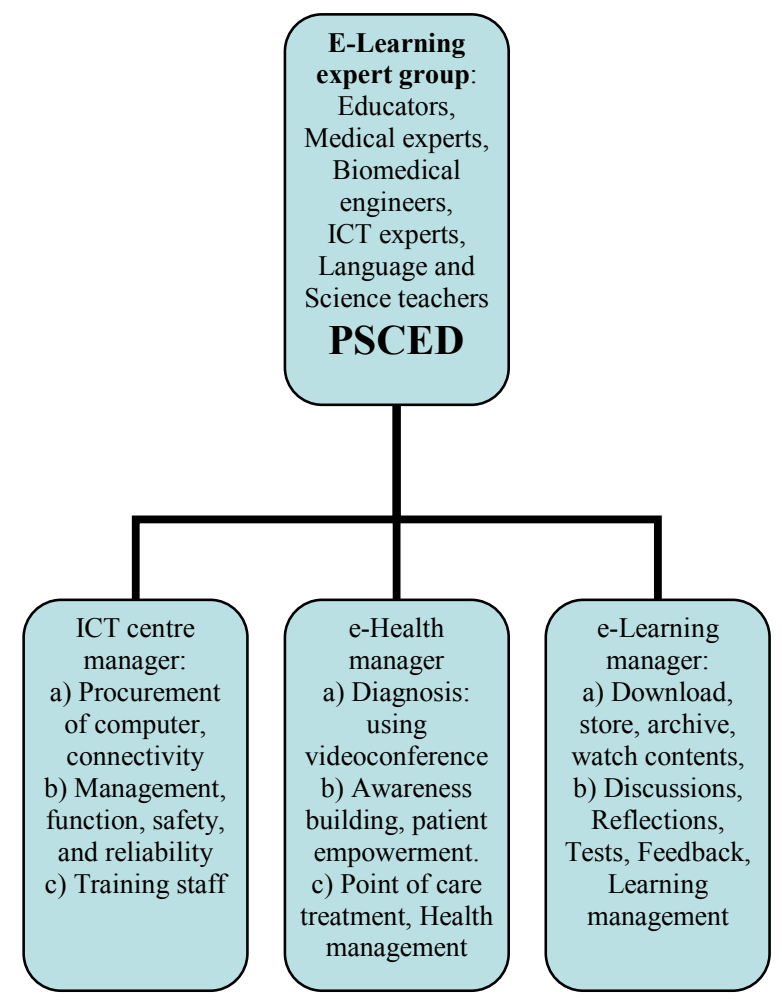

Fig. 1: Organizational structure of the rural ICT for promoting e-Health and eLearning. Expert group does the Planning, Selection, Creation, Evaluation and Dissemination work (PSCED) and the local management team works with well-defined line of responsibility and mechanisms of accountability.

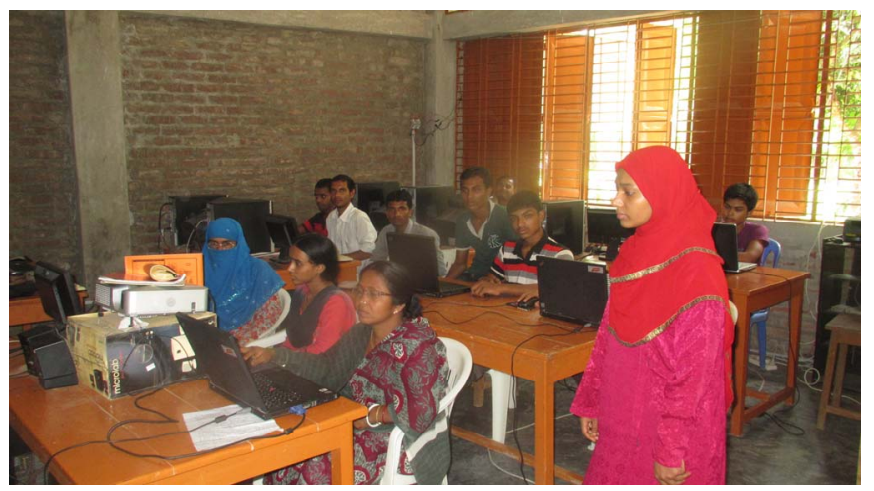

Picture 4: ICT training centre for empowering rural youth with computer and internet use training. Instructor has to be trained to manage the learners' attitude to new technology as well as requires awareness and ability to match cultural and religious influences.

Our work for empowerment and involvement of the rural community to improve education and health care included: a) periodic training spread over 3-6 months, b) follow-up technical assistance programme that supports incorporation of technology into educational projects and c) series of seminars intended to deepen teachers' and health workers' understanding of the use of ICT in teaching and learning. Face to face experts' consultations are given routinely using videoconference facility for empowering the teachers, students, health workers and patients. 


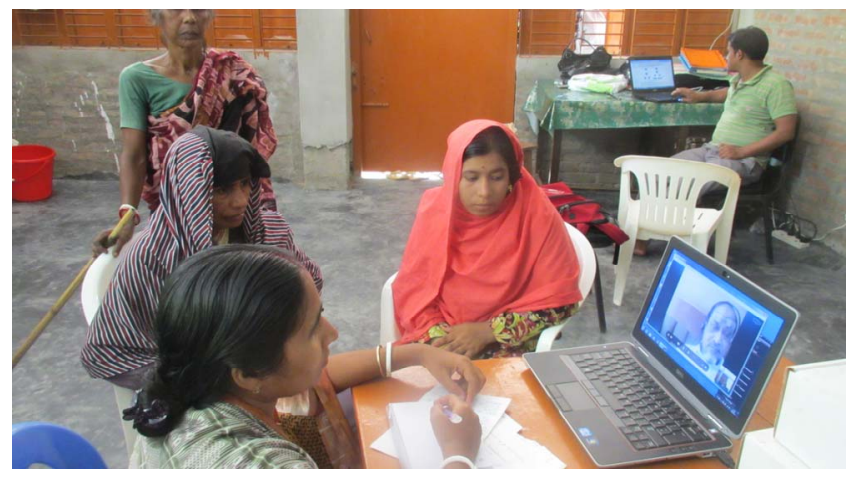

Picture 5: At the e-Health center, patients get quality diagnostic tests, and experts' advice for treatment, disease prevention and health management over videoconference system

Appropriate videoconference links are selected, sometimes also created to address the local needs for awareness creation and to develop English language proficiency, increasing understanding for science and management of health and prevention of diseases.

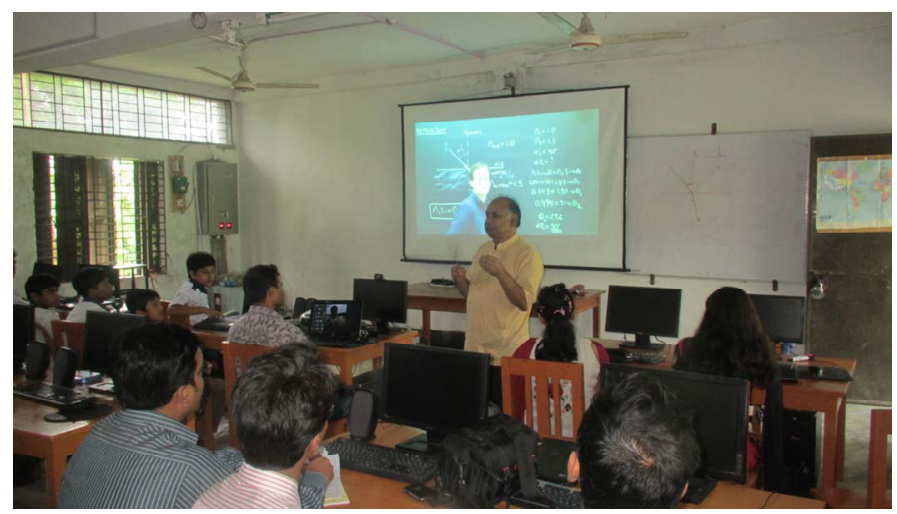

Picture 6: Professor Amirul Alam Khan, Chairman, Jessore Board, lecturing on the importance of integrating e-Learning with face-to-face interactions at NUHAT e-Learning center.

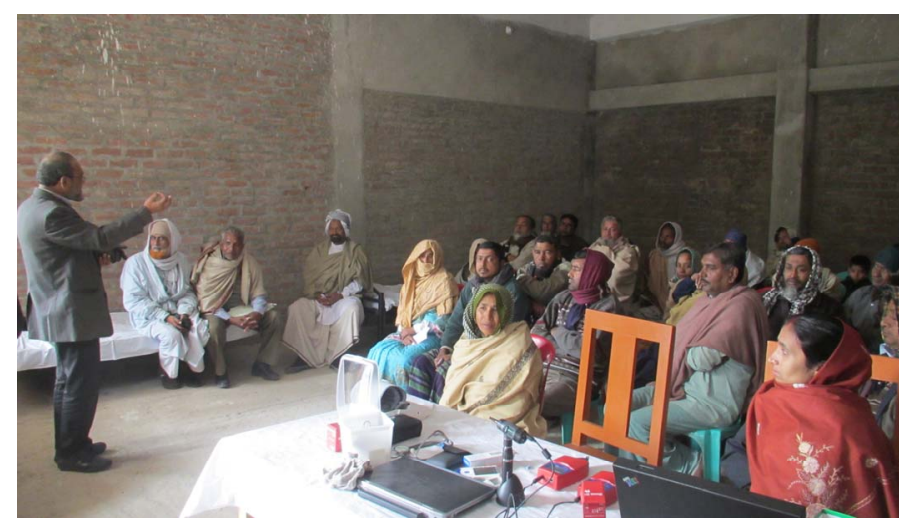

Picture 7: Dr. Saiful Islam meets patients and health care providers twice a week over videoconference system and also visits for face- to- face seminar for creating awareness on management of health.
IV.

\section{RESULTS AND DISCUSSIONS}

The centre has been functioning as a training unit for Computer and Internet education as well as facilitating eLearning and e-Health activities to empower the rural people. We provided computers, Internet and digital resources, diagnostic devices for recording vital physiological parametrs to the ICT training centres. We have started the process of enabling teachers and health workers to take advantage of the potential of ICT, for their personal use and for their professional activities. We train all students to use ICT tools and access e-learning materials for their empowerment. While working with ICT tools for empowering the rural people in Bangladesh, some of the challenges faced include, unreliability of electricity supply, weak internet backbone, high internet access cost, financial constraints preventing the purchase of an appropriate number and type of ICT equipment, unavailability of adequate number of computerliterate employees to implement e-health programme, resistance to changes.

We considered the experiences and suggestions from various groups working with e-Learning and e-Health and included success factors in our work, such as:

-High-level support: A key success factor for e-Learning and e-Health applications is support from high levels within the public sector and we involved all the governmental leaders into this work (figure 6) and got support to implement the plans.

-User friendly interface: Most of the e-Learning applications around the world are usually operated in English. In some places this is appropriate, but in many others it is not.

-Meeting stakeholder needs: A vital part of this e-Learning application's success comes from its being designed to meet the specific interests of a number of different stakeholders.

-Start from the lives of citizens: Utilisation of ICTs in rural areas should mainly be targeted at the needs, demand and interest of the local people to get them actively involved to improve the effectiveness of the service delivery. We try to select the digital contents to match the interests and needs of the target groups and blend with face to face lessons.

At the pilot school, significant improvements in teachers' teaching practices are found. Dropout rates among students lowered, English language proficiency among students and teacher have improved, global understanding among students have developed. Among the teachers and the students, the computer and ICT tools management skills have developed and internet use has been increased. Interest for elearning has developed, and the students readily use Computer, Internet and e-Leaning materials, and also discuss the contents in groups for sharing, better understanding and to replicate and create new knowledge and skills. It is also expected that significantly higher $\%$ of the school graduates will get admitted to attractive higher education centers at home and abroad. 


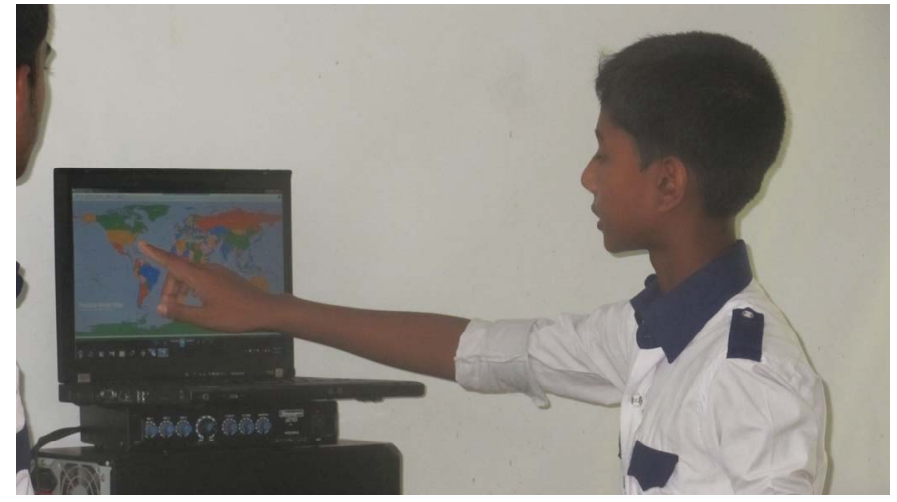

Picture 8: Rural tudents using laptop for global studies and access relevant content for learning English language and science.

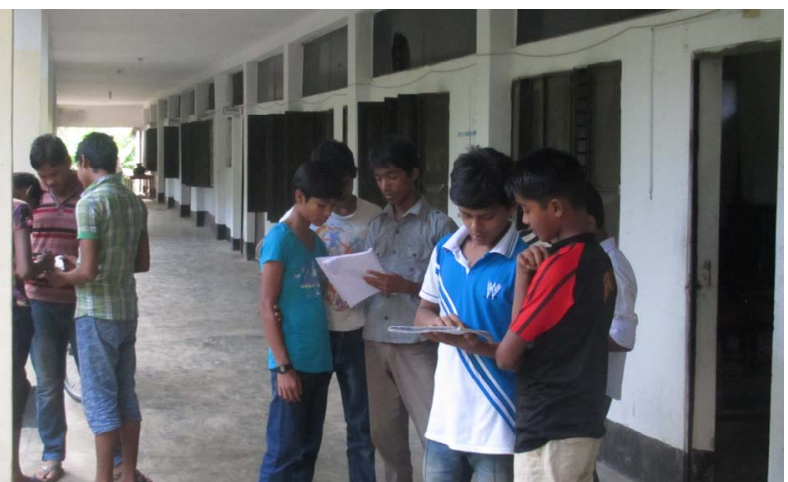

Picture 9: Students are working in group with mentors to solve problem introduced in the e-Learning classes.

Our evaluation work based on the following five criteria used by others [4]: effectiveness, timeliness, sustainability, equity, and technical feasibility. For each criterion, we assign a rank of weak, medium, or strong. The results from our work gave us four strong in four categories, and medium in technical feasibility. Most of the learning materials available in the website are developed in western countries or with limited relevancy in terms of content and language. We have taken initiatives to develop demand driven and relevant content in English and Bengali language addressing the given educational curriculum.

\section{A. Challenges}

Mobile Internet has also been implemented in Bangladesh but there are many obstacles to extend ICT to rural areas, such as:

a) Electricity supply is yet to be provided to the most of the villages, and uninterrupted supply of electricity has not been ensured to the rural areas with electricity.

b) Although some of the semi-urban places like districts and sub-districts have access to the Internet, most of the people in the majority of the areas are yet to be connected, and there no well-organized programme to train people to develop their ICT skills. c) Most rural people are not literate to use an all-English based ICT system.

d) Internet is very expensive. Most people of the rural areas cannot afford to have a computer and Internet due to high price.

e) Digital division within the country is enormous. Although most people live in the countryside, they are excluded from many of the facilities available in the urban areas. Constrains in the current ICT infrastructure must be overcome to fully expand E-Learning actively. The constraints can be summarized as; High percentage of illiteracy, Low computer penetration, lack of continuous and uninterrupted supply of electricity, Weak data communication infrastructure, Poor public awareness about ICT, Lack of adequate skilled human resources.

\section{B. Prospects}

Despite of the various constraints, Bangladesh has been progressing in the right direction in computer utilization in various fields. Sub marine Optical Fiber backbone network is expected to provide the people with the necessary bandwidth in affordable cost to access E-Learning resources. By the end of 2013 3G Present government's vision for "digital Bangladesh" has created a lot of positive steps to increase the use of ICT. There is a plan to further reduce the cost of Internet connectivity to increase the use of INTERNET and reduce the digital divide. We need to face the challenges and eliminate the constraints with international collaboration across the disciplines involving the public and private partnership to utilize

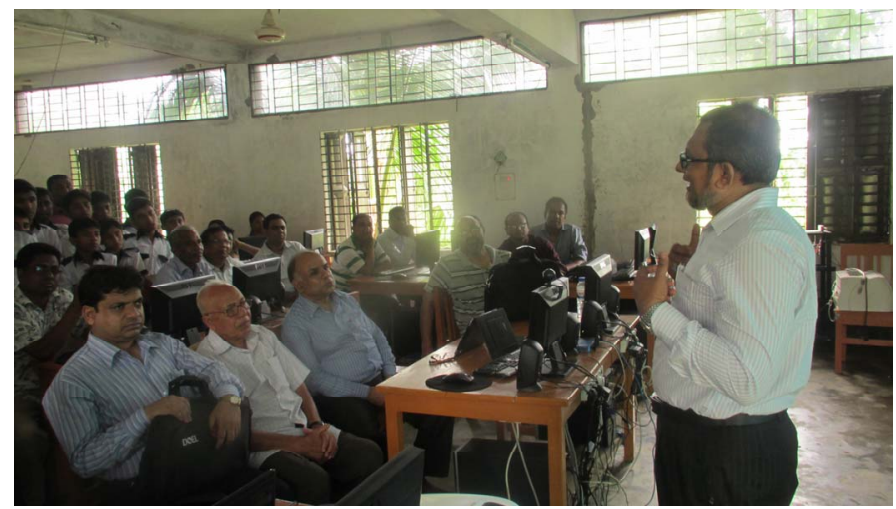

Picture 10: Engineering Sultan Reza from Grameen Phone is explaining about the need to improve connectivity for better e-Learning services.

the enormous benefits of e-Learning that provides with the opportunities to access the most up to date information and/ technology worldwide which are not achieved through traditional system. It helps development of Human Resources up to a global standard. We find increased interest among young students in global education, international jobs and world affairs. We believe, within a few years, many more students and skilled workers from rural areas will go abroad for higher education in various fields or to obtain well-paid 
jobs and thus digital divide between rural and urban areas will be reduced.

We are developing E-Learning content to enhance teachers' knowledge considering several aspects such as, to develop skills for curriculum integration; to develop classroom pedagogic practices through the use of lesson planning, students-centred learning techniques, and interactive teaching methods; and to help teachers make teaching and learning resources from locally available context/material. While developing content, it is important to focus on the four important pillars of education, like learning to solve problems, critical thinking, decision making, understanding consequences, as well as developing personal and social abilities and manual skills [6].

\section{CONCLUSIONS}

Regardless of not yet affordable cost of ICT tools, unreliable electricity supply, shortage of ICT experts, lack of knowledge about the potential benefits of ICT, we are highly optimistic about the huge potentials of e-Learning for opening the windows of opportunities for the marginalized, remote and rural people in the developing countries like Bangladesh. ELearning increases educational equity by creating access to the high quality teacher also for the students who do not afford to pay for the private tutors. Some teachers find this as a threat to their income though. Our work demonstrates potential role of e-Learning in enhancing the current health and education system in rural Bangladesh where rural teachers, students and health workers and patients are getting expert consultation, education and training. The young students have developed excellent skill to manage ICT tools and are now functioning as mentors at the learning center. Our work is making true impacts in the rural areas:

1) Poor women are getting quality treatment from the medical consultants in the cities.

2) Rural health workers are empowered by ICT tools and are able to get help to manage illnesses.

3) Rural people are getting health information from regular seminars about management health and disease prevention.
4) Rural teachers are getting help with teaching materials and methods from national and international experts

5) Rural students are able to communicate in English and can comfortably and independently search Internet for their relevant information.

The ICT services can be replicated to any other regions with access to Electricity, Computer, and Internet connectivity. The quality and reliability of the services can be improved by ensuring uninterrupted electricity supply and affordable, reliable backbone network with broadband connectivity and a well-trained management team. Organizations from both public and private sectors may follow our example of collaboration and take the necessary initiative as early as possible to get the affordable, complete, sustainable benefits from the system.

\section{ACKNOWLEDGMENT}

We gratefully acknowledge the financial support from SPIDER (www.spider.org) and SIDA (www.sida.se).

\section{REFERENCES}

[1] G. Eason, B. Noble, and I.N. Sneddon, "On certain integrals of Lipschitz-Hankel type involving products of Bessel functions," Phil. Trans. Roy. Soc. London, vol. A247, pp. 529-551, April 1955. (references)

[2] J. Clerk Maxwell, A Treatise on Electricity and Magnetism, 3rd ed., vol. 2. Oxford: Clarendon, 1892, pp.68-73.

[3] I.S. Jacobs and C.P. Bean, "Fine particles, thin films and exchange anisotropy," in Magnetism, vol. III, G.T. Rado and H. Suhl, Eds. New York: Academic, 1963, pp. 271-350.

[4] K. Elissa, "Title of paper if known," unpublished.

[5] R. Nicole, "Title of paper with only first word capitalized," J. Name Stand. Abbrev., in press.

[6] Y. Yorozu, M. Hirano, K. Oka, and Y. Tagawa, "Electron spectroscopy studies on magneto-optical media and plastic substrate interface," IEEE Transl. J. Magn. Japan, vol. 2, pp. 740-741, August 1987 [Digests 9th Annual Conf. Magnetics Japan, p. 301, 1982].

[7] M. Young, The Technical Writer's Handbook. Mill Valley, CA: University Science, 1989. 